\title{
HIGH-TEMPERATURE PHASE TRANSFORMATIONS AND DYNAMICS OF ZnO NANOPARTICLES INCORPORATED 4- CYANO-4'-PENTYLBIPHENYL MESOGEN
}

\author{
K.V. Surya Narayana Raju, S. Salma Begum, B. Dharma Sagar \\ and Shaik. Babu \\ Department of Physics, K. L. University, Vaddeswaram-522502, Andhra Pradesh. \\ *E-mail: babu.computers@gmail.com
}

\begin{abstract}
Synthesis of Zinc Oxide nanoparticles through chemical precipitation method was done taking aqueous solutions of Zinc Nitrate and Sodium Hydroxide as precursors. Elemental, structural and optical absorption studies of the ZnO nanoparticles were investigated using Energy Dispersive, X-Ray Diffraction and UV-Visible spectroscopy. The prepared nanoparticles were studied for their effect on familiar display device materials called liquid crystal/mesogen. $\mathrm{ZnO}$ nanoparticles were introduced in the lattice of 4-cyano-4'-pentylbiphenyl (5CB) mesogen through dispersion technique. $\mathrm{ZnO}$ nanoparticles incorporated 5CB is characterized through Polarizing Optical Microscopy, X-Ray Diffraction and Image Analysis using MATLAB software. From these studies, it was revealed that the presence of $\mathrm{ZnO}$ nanoparticles in liquid crystal enhanced the properties of pure 5CB. It was observed that the transition temperatures and crystallinity of $\mathrm{ZnO}$ nanoparticles incorporated mesogens were remarkably increased when compared to the pure counterpart which is a preferable feature in terms of the application of these samples. In addition, novel phases were observed in the doped liquid crystal sample at very high temperatures. These changes are assigned to the enhanced surface area to volume ratio of nanoparticles, which in turn improves their catalytic activity. ZnO nanoparticles incorporated 5CB mesogen is one among the liable materials for display devices and biosensor applications due to reduced energy consumption.
\end{abstract}

Keywords: ZnO nanoparticles, Precipitation method, 5CB Liquid Crystal, Image Analysis

(c) RASĀYAN. All rights reserved

\section{INTRODUCTION}

Reduction in power consumption, getting required properties at low applied voltages and thermal stability of existing phases are the key factors for energy applications of the present soft matter. Liquid Crystal materials generally possess applications in display technology and biosensor devices ${ }^{1-3}$. Sometimes, pure liquid crystals may not satisfy all the above said features for energy applications. Doping is one of the key technique to resolve the problem related to thermal conductivity, electrical conductivity, optical absorption etc., However, smart materials also play major role in tuning the existing physical properties of soft matter in terms of phase transition temperatures, phases, enthalpy, entropy, specific heat, grain size, interplanar spacing, etc., Nanoparticles are very much preferable for doping due to their high catalytic activity and small size that can fit into the interstices of host lattice. Doping of nanoparticles in the liquid crystal matrix also resolves the process of sub-hertz frequency dielectric absorption that is activated thermally ${ }^{4}$ and improves switching characteristics and spontaneous polarization ${ }^{5}$. Nanoparticles dispersed liquid crystals can be effectively tunable with refractive indices from negative through zero to positive values. Twisted nematic liquid crystal device cell can be fabricated by doping nanoparticles with some liquid crystal molecules ${ }^{6-7}$ which exhibit a frequency modulation response to applied voltage waveform. Generally, submicron particles do not disturb the liquid crystal alignment and doped suspensions macroscopically appear like pure liquid crystal with no readily apparent evidence of dissolved particles. However, these kinds of suspensions possess enhanced dielectric anisotropy and sensitive to external electric field ${ }^{8}$. Researchers also found enhancement in photoluminescence intensity in metal nanoparticles doped liquid crystal which is a breakthrough for the development of high brightness photoluminescent liquid crystal 
displays, high contrast, large view angle and less backlight scattering ${ }^{9-11}$.In this communication, we are presenting the effect of metal oxide (zinc oxide) nanoparticles on the molecular alignment, thermal properties and crystallinity of 4-Cyano-4'-Pentylbiphenyl Mesogen (5CB), which is a well-known room temperature nematic liquid crystal. Experimental data have been obtained using a polarizing optical microscope, X-ray diffraction and Image analysis by MATLAB software. The observations are correlated with that of the pure counterpart. Priority of $\mathrm{ZnO}$ as our dopant depends on the following literature. $\mathrm{ZnO}$ is an II-VI compound n-type semiconductor. It has a wide band gap of $3.37 \mathrm{eV}$ and large exiton binding energy of $60 \mathrm{meV}$. It exhibits high electrical conductivity, high infra-red reflectance and high visible transmittance, which make $\mathrm{ZnO}$ to be useful over a wide variety of applications including electronic, optoelectronic devices, gas sensors, transparent conducting electrodes, laser diodes, thin film transistors, UV \& blue LEDs, surface acoustic wave devices, display devices, and catalysis etc ${ }^{12-15}$. Further, it is inexpensive, abundant in availability and environmentally friendly, when compared to other wide band gap semiconductors ${ }^{16}$. It has a stable wurtzite structure with lattice spacing $a=3.249 \mathrm{~A}^{\mathrm{o}}$ and $\mathrm{c}=5.205 \mathrm{~A}^{\mathrm{o}}$ and tetrahedrally-coordinated $\mathrm{O}^{2-}$ and $\mathrm{Zn}^{2+}$ ions are stacked alternately along the c-axis. The n-type semiconductor behavior of $\mathrm{ZnO}$ can be attributed to the ionization of excess zinc atoms in interstitial positions and the oxygen vacancies. The structure of $\mathrm{ZnO}$ is also known for its surface defects and hence increases in the active sites ${ }^{17}$, which makes it more suitable to combine with other structures to exhibit novel properties. Recently, nanocrystalline materials are under extensive study due to their unique properties and immense potential application in developing novel materials and nano device fabrication. Zinc Oxide Nanoparticles can be synthesized by various techniques like Ball-Milling, Precipitation, Sol-Gel, HydroThermal, etc., However, Precipitation Method is the best technique as it is simple, non-harmful to the environment, inexpensive. ${ }^{18-19}$

\section{Materials and Methods}

\section{EXPERIMENTAL}

Present study dealt with the influence of nanoparticles over liquid crystal matrix. A well-known room temperature liquid crystal (4-cyano-4'-pentyl biphenyl) was purchased from Merck, China. Materials used for the synthesis of Zinc Oxide nanoparticles are as follows: Zinc nitrate hexahydrate $\left(\mathrm{Zn}\left(\mathrm{NO}_{3}\right)_{2} \cdot 6 \mathrm{H}_{2} \mathrm{O}\right)$, sodium hydroxide $(\mathrm{NaOH})$ were purchased from Merck, India and used without further purification. DI water was used as a solvent.

\begin{tabular}{l|l|c|c}
\hline Materials & Company & Initial Purity & Final Purity \\
\hline $5 \mathrm{CB}$ & Merck & 99.9 & 99.9 \\
\hline $\mathrm{Zn}\left(\mathrm{NO}_{3}\right)_{2} .6 \mathrm{H}_{2} \mathrm{O}$ & Merck & 99.9 & 99.9 \\
\hline $\mathrm{NaOH}$ & Merck & 99.9 & 99.9 \\
\hline
\end{tabular}

No further purification was done to these samples as they have purchased from Merck, India.

\section{Preparation of $\mathrm{ZnO}$ nanoparticles}

To prepare $\mathrm{ZnO}$ nanoparticles simple chemical precipitation technique was adopted. No capping agents were used during the synthesis process. $0.2 \mathrm{M}$ zinc nitrate solution was prepared by dissolving $\mathrm{Zn}\left(\mathrm{NO}_{3}\right)_{2} .6 \mathrm{H}_{2} \mathrm{O}$ in $25 \mathrm{ml}$ DI water at room temperature. $50 \mathrm{ml}$ DI water was added to this solution. $25 \mathrm{ml}$ $1 \mathrm{M} \mathrm{NaOH}$ sol was added slowly to the above solution maintaining the temperature at $60^{\circ} \mathrm{C}$. The mixture of solutions was stirred for $2 \mathrm{~h}$ at $60^{\circ} \mathrm{C}$, resulting in a white precipitate. The precipitate was washed with DI water several times till the $\mathrm{pH}$ reached neutral ${ }^{17-18}$ and it was collected by centrifugation. The collected samples were initially dried at $60^{\circ} \mathrm{C}$ for $12 \mathrm{~h}$ and then annealed at $500^{\circ} \mathrm{C}$ for $2 \mathrm{~h}$ in an air atmosphere. Prepared nanoparticles were characterized through EDX and XRD.

\section{Preparation of nanoparticles incorporated liquid crystal (n5CB)}

Synthesized Zinc Oxide nanoparticles were introduced in the lattice of 4-cyano-4'-pentyl biphenyl (5CB) through doping in $1 \mathrm{wt} \%$ ratio. $5 \mathrm{CB}$ and $\mathrm{ZnO}$ nanoparticles were weighed separately and taken in a beaker 
in 100:1 wt ratio respectively. The mixture is kept under stirring at $40^{\circ} \mathrm{C}$ for one hour such that nanoparticles can evenly disperse in the 5CB matrix. A drop of nanoparticles incorporated liquid crystal (n5CB) was put on a glass slide (rubbed for planar alignment of the sample) and covered with a glass sticker such that prepared sample is uniformly aligned on the glass substrate. This is then kept under hot stage connected to a variac for temperature variation. Hot stage with the sample was kept under eyepiece of Meopta Polarizing Optical Microscope (POM) attached with a Sony digital camera to take photographs of textures at different temperatures. POM was kept in crossed polarizers position such that the texture of sample can be visualized perfectly ${ }^{20-22}$. The sample was heated slowly @ $2^{0} \mathrm{C} / \mathrm{min}$ using a variac and digital photos of textures were taken for every $2^{\circ} \mathrm{C}$ rise in temperature. Phases and phase transition temperatures starting from room temperature and ending with isotropic phase were noted systematically. All these photos were analyzed and dynamics of textures were calculated through MATLAB 2013 version software. Crystallinity and grain size $^{23}$ of n5CB were calculated through powder X-Ray Diffraction technique.

\section{RESULTS AND DISCUSSION}

In the present work, we report the elemental, structural and optical absorption studies of $\mathrm{ZnO}$ nanoparticles synthesized.

\section{EDS Analysis}

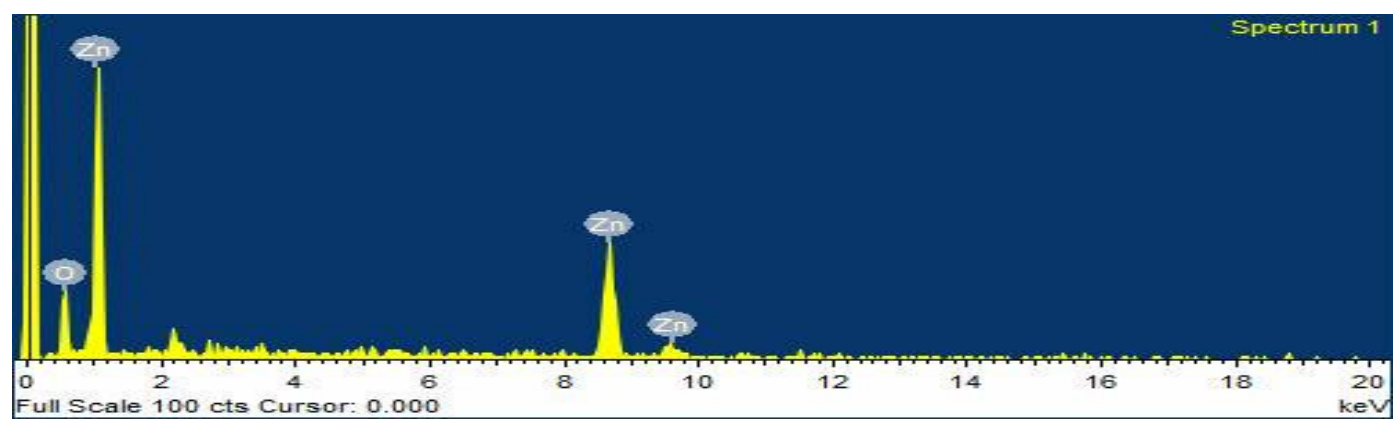

Fig.-1: Energy dispersive spectra of $\mathrm{ZnO}$ nanoparticles

Energy dispersive spectra of $\mathrm{ZnO}$ nanoparticles are represented in Fig.-1. EDS spectra confirm the elements $(\mathrm{Zn}$ and $\mathrm{O})$ present in the nanoparticles and no significant traces of other residuals are found.

\section{XRD Analysis}

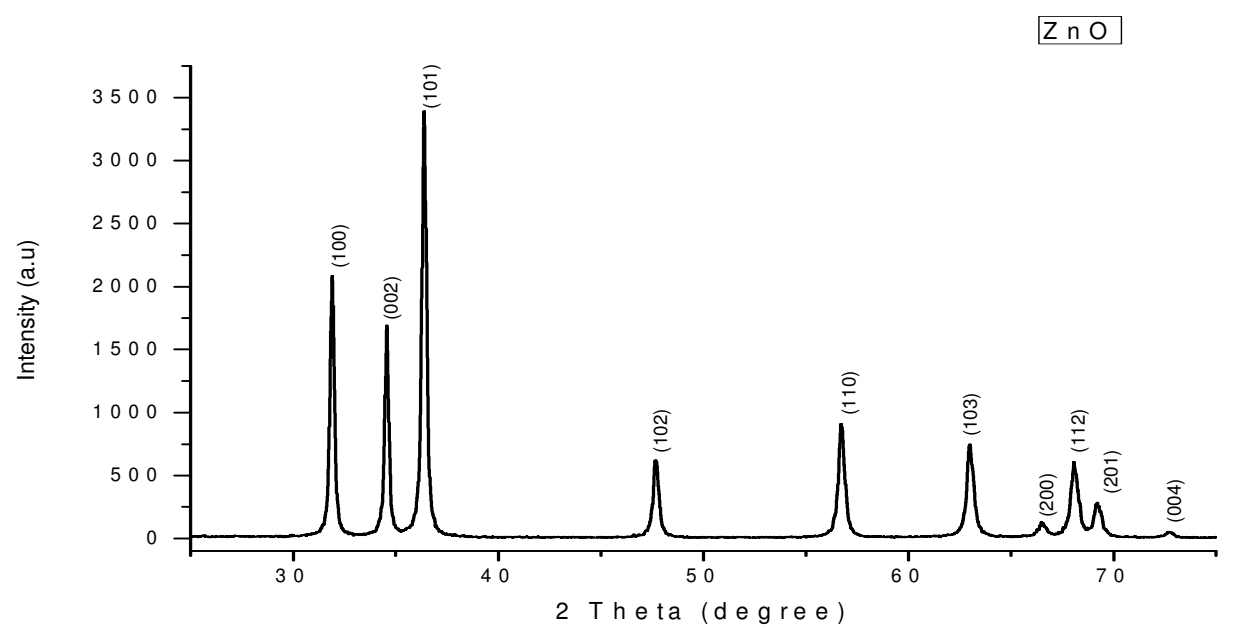

Fig.-2: XRD patterns of $\mathrm{ZnO}$ nanoparticles 
RASĀYAN J. Chem.

Vol. 10 | No. 1 |37-45 | January - March | 2017

$\mathrm{X}$-ray diffraction patterns of $\mathrm{ZnO}$ nanoparticles are represented in fig.2. The peaks designated indicate the wurtzite structure with the hexagonal phase of $\mathrm{ZnO}$ (space group P63mc, and JCPDS no. 36-1451). Further, the sharp diffraction peaks represent the good crystallinity of nanoparticles and no characteristic peaks due to impurities and other phases are observed. The average size of nanoparticles is determined by using Scherrer formula, which is around $34 \mathrm{~nm}$.

\section{UV-Vis Absorption Spectrum}

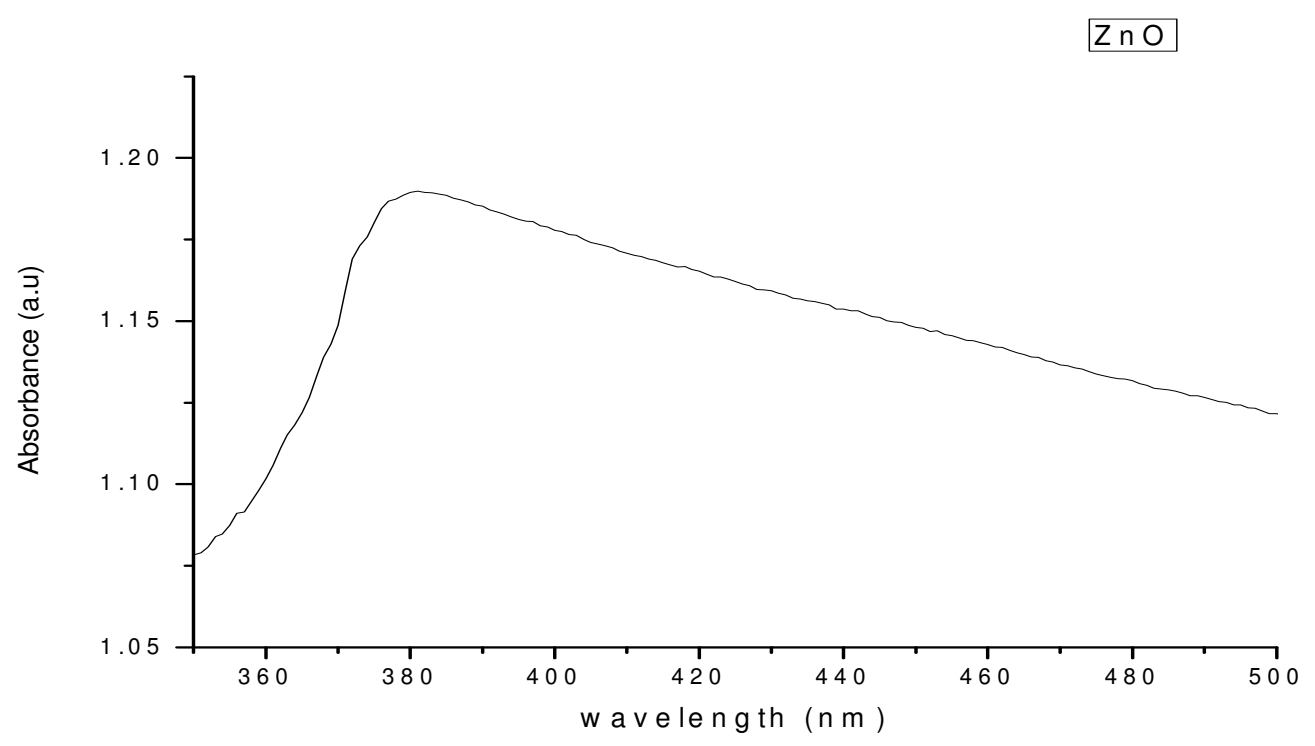

Fig.-3: UV-Vis absorption spectrum of $\mathrm{ZnO}$ nanoparticles

The UV-visible absorption spectrum of $\mathrm{ZnO}$ nanoparticles is represented in fig.3. Optical absorption provides a scope to understand the optical properties of the materials. A strong absorption peak is observed at $381 \mathrm{~nm}$, which corresponds to an energy gap of $3.25 \mathrm{eV}$.

Present communication also involves the influence of zinc oxide nanoparticles on the thermal, structural and optical properties of room temperature nematic liquid crystal 4-cyano-4'-pentyl biphenyl (5CB). The temperature range of nematic phase of $5 \mathrm{CB}$ is $20^{\circ} \mathrm{C}-50^{\circ} \mathrm{C}^{24-25}$. It is also found in our recent work, that it is very sensitive to biomolecules like glucose ${ }^{26}$ and suggested to biosensor applications. Now, the same 5CB is tested with the inclusion of $\mathrm{ZnO}$ nanoparticles. Astonishingly, a drastic change is found in transition temperatures and novel texture in the $\mathrm{ZnO}$ nanoparticle doped $5 \mathrm{CB}(\mathrm{n} 5 \mathrm{CB})$ liquid crystal material. A stable smectic $\mathrm{C}^{*}$ phase in $\mathrm{n} 5 \mathrm{CB}$ at room temperature is found that sustains up to $175^{\circ} \mathrm{C}$, which is a unique observation and is due to the doping $\mathrm{ZnO}$ nanoparticles, leading to the enhancement of transition temperatures. Novel texture observed in the doped sample is because of the molecular interaction of nanoparticles with pure liquid crystal molecules. In addition to the nematic phase, observed in both samples, n5CB exhibits smectic $\mathrm{C}^{*}$ phase also. Further, $\mathrm{n} 5 \mathrm{cB}$ enters into the isotropic state at an even very high temperature $\left(350^{\circ} \mathrm{C}\right)$, which is a significant change due to the inclusion of nanoparticles.

Hence, these results confirm the existence of novel texture $(\mathrm{Sm} \mathrm{C}$ ) for long duration and very high transition temperatures in $\mathrm{n} 5 \mathrm{CB}$, when compared to its pure counterpart. Above results have been studied through Polarizing Optical Microscope in crossed polarizer position. Transition temperatures of pure and $\mathrm{ZnO}$ nanoparticles doped 5CB were tabulated in Table-1. Textures of $\mathrm{Sm} \mathrm{C*}$ and nematic phases of n5CB were shown in figures- 4 and 5 respectively.

The observed textures were recorded as digital photos using Sony camera for every $5^{\circ} \mathrm{C}$. All the recorded photos were then analyzed using MATLAB software. In this image analysis, we have calculated various mathematical and physical parameters like mean, variance, skewness, kurtosis, entropy, absorption coefficient and birefringence ${ }^{27-28}$. These parameters have physical significance in terms of image intensity. 
RASĀYAN J. Chem.

Vol. 10 | No. 1 |37-45 | January - March | 2017

Results of above said parameters are for pure and nanoparticles doped 5CB that are shown in figure6. Formulae used to calculate Entropy, absorption coefficient and birefringence are given below as rest of the basic parameters were obtained from MATLAB code.

Table-1: Transition temperatures of 5CB and $\mathrm{ZnO}$ nanoparticles doped 5CB (n5CB)

\begin{tabular}{c|c|c|c|c}
\hline Sample & $\mathrm{T}_{\mathrm{CN}}$ & $\mathrm{T}_{\mathrm{NI}}$ & $\mathrm{T}_{\mathrm{IN}}$ & $\mathrm{T}_{\mathrm{NC}}$ \\
\hline $5 \mathrm{CB}$ & 25 & 48 & 40 & 23 \\
\hline \multirow{2}{*}{$\mathrm{n} 5 \mathrm{CB}$} & $30\left(\mathrm{~T}_{\mathrm{CSm} \mathrm{C}^{*}}\right)$ & 350 & 340 & $170\left(\mathrm{~T}_{\mathrm{NSmC}}\right)$ \\
\cline { 2 - 3 } & $175\left(\mathrm{~T}_{\mathrm{SmC}^{*} \mathrm{~N}}\right)$ & & & $30\left(\mathrm{~T}_{\mathrm{SmC}^{*} \mathrm{C}}\right)$ \\
\hline
\end{tabular}

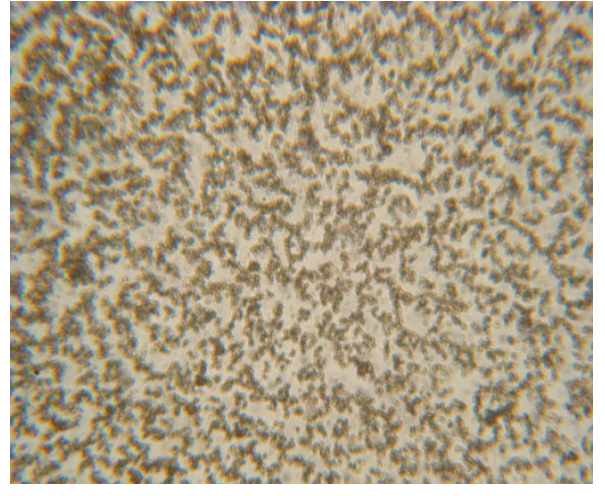

Fig.-4: $\mathrm{SmC}^{*}$ phase of $\mathrm{n} 5 \mathrm{CB}$ at $100^{\circ} \mathrm{C}$

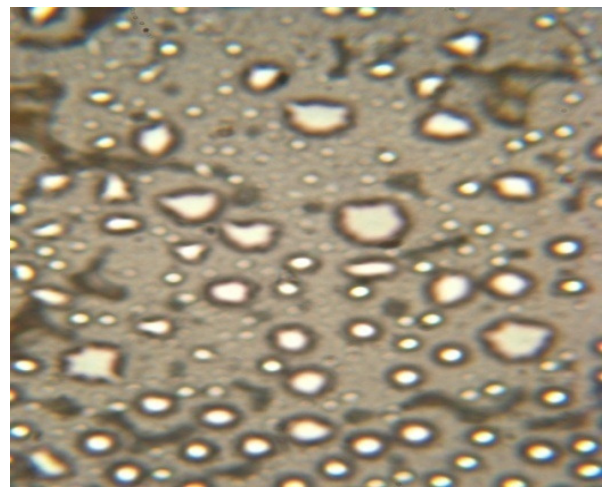

Fig.-5: Nematic phase of $n 5 \mathrm{CB}$ at $270^{\circ} \mathrm{C}$

\section{Entropy}

Entropy is the measure of randomness of the gray levels in an image. The entropy of an image is calculated by finding the probability of a particular gray level value found in that image-

\section{Absorption Coefficient}

$$
\text { Entropy }=-\sum_{i=1}^{m} \sum_{j=1}^{n} P_{(i, j)} \log \left(P_{(i, j)}\right)
$$

Absorption Coefficient (AC) measures the optical absorbance property of the image. It is related to the intensity of incident and transmitted light and also on the thickness of the sample.

\section{Birefringence}

$$
\mathrm{AC}=\frac{1}{d} \log \left[\frac{I_{0}}{I}\right]
$$

Birefringence $(\Delta \mathrm{n})$ is the property that shows the capacity of the sample to split the incident light into eray and o-ray.

$$
\Delta \mathrm{n}=\frac{\lambda}{\pi d} \sin ^{-1}\left(\sqrt{\frac{I}{I_{0}}}\right)
$$

In all the above image analysis studies, we have found remarkable changes in $\mathrm{n} 5 \mathrm{CB}$ compared to its pure counterpart. In detail, the mean values of n5CB increases, which in turn increase optical transmittance of the material. Variance, Skewness, Kurtosis and Entropy of $n 5 \mathrm{CB}$ were found decreased compared to pure $5 \mathrm{CB}$. Also, it is found that absorption coefficient of $\mathrm{n} 5 \mathrm{CB}$ was decreased and finally its birefringence values were significantly increased.

From Figure-6, we can certainly draw following conclusions:

For $5 \mathrm{CB}$, in all the graphs of mean and variance, skewness and kurtosis a significant peak was observed at a temperature around $37^{\circ} \mathrm{C}$. Whereas for $n 5 \mathrm{CB}$ in the same studies the significant peak was observed at a temperature around $180^{\circ} \mathrm{C}$. For $5 \mathrm{CB}$, it is observed that entropy is maximum at $35^{\circ} \mathrm{Cand}$ fluctuates from $40^{\circ} \mathrm{C}-45^{\circ} \mathrm{C}$ and finally shows maximum value at isotropic phase. For $n 5 \mathrm{CB}$, it is observed that entropy is continuously fluctuating from room temperature to $180^{\circ} \mathrm{C}$ and finally shows a significant peak at $180^{\circ} \mathrm{C}$ and then decreases. The absorption coefficient of $5 \mathrm{CB}$ at different temperatures was found a significant dip at 
a temperature around $35^{\circ} \mathrm{C}$ and finally increases when moving to the isotropic phase. The absorption coefficient of $n 5 \mathrm{CB}$ has shown a significant dip at around $200^{\circ} \mathrm{C}$ and then smooth peaks with decreased values of absorption coefficient were observed while moving to the isotropic phase. Birefringence was calculated for RGB colors taking their independent $\lambda$ values. For $5 \mathrm{CB}$, maximum birefringence $(0.0006)$ was observed at $37^{\circ} \mathrm{C}$, whereas, n5CB exhibited maximum birefringence $(0.00094)$ at $180^{\circ} \mathrm{C}$.

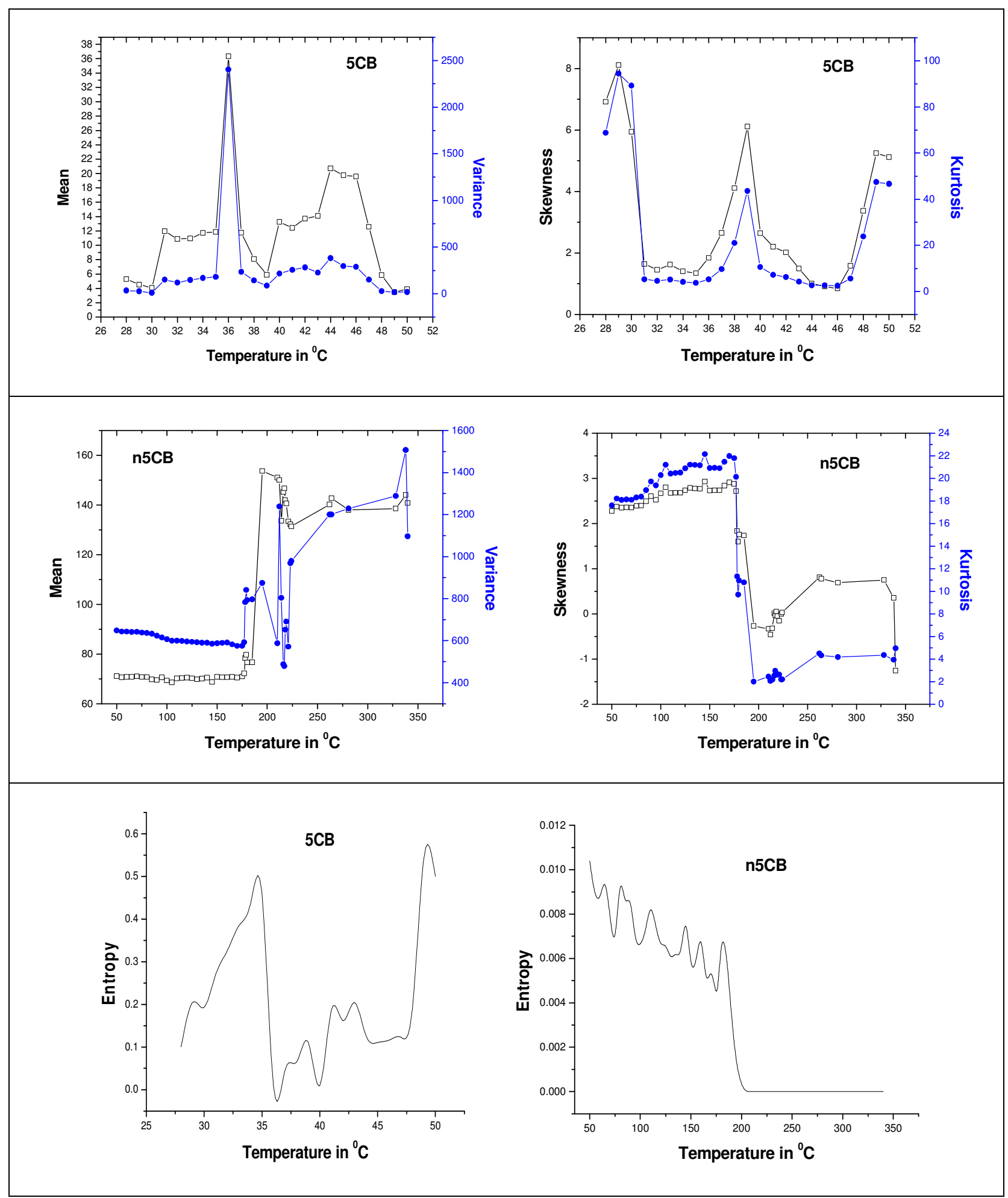


RASĀYAN $J$. Chem.

Vol. 10 | No. 1 |37-45 | January - March | 2017

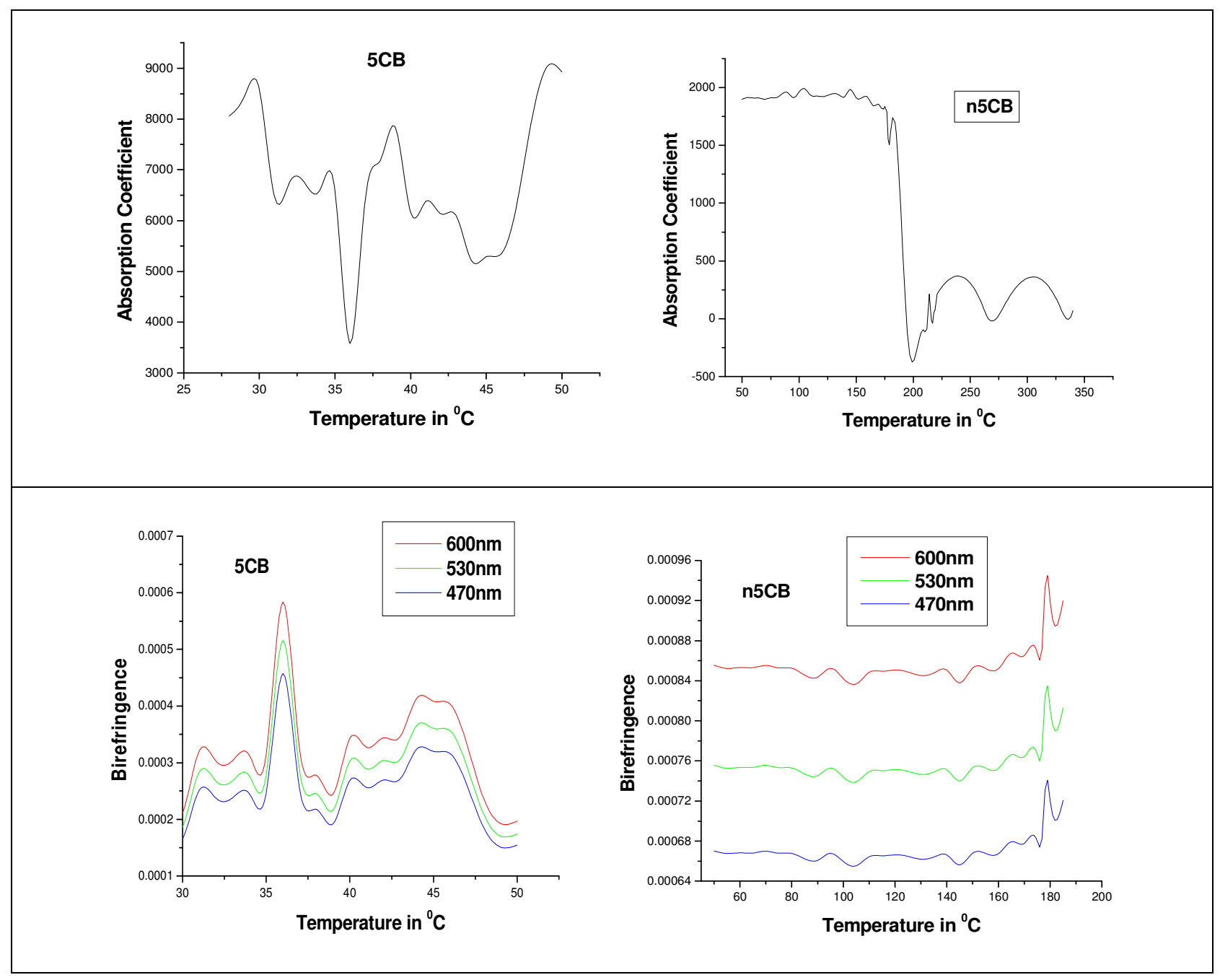

Fig.-6: Image analysis studies of 5CB and $\mathrm{ZnO}$ nanoparticles doped 5CB (n5CB)

Image analysis of pure 5CB and $\mathrm{ZnO}$ nanoparticles doped $5 \mathrm{CB}$ was done through which various parameters were calculated and are plotted as shown in Figure 6. From these studies, we have observed that parameters named mean, variance, skewness, and kurtosis have shown a significant peak at around transition temperature of the sample and from these values also, we can confirm the transition temperatures of the taken samples. Also, entropy, absorption coefficient, and birefringence were calculated for both 5CB and n5CB through Image analysis. All these values reveal that significant peaks of nano-doped 5CB (n5CB) were observed at high temperatures compared to that of pure counterparts. Hence, we can conclude that presence of Zinc Oxide nanoparticles in the lattice of 5CB liquid crystal made it enhance the transition temperatures to a larger extent and various optical parameters also have been changed remarkably.

Finally, with our knowledge, all these conclusions reveal that our synthesized Zinc Oxide nanoparticles have a significant effect on the lattice of $5 \mathrm{CB}$, which is the main reason to all these variations ${ }^{29}$. To confirm this analysis, we have done X-Ray Diffraction to pure and $\mathrm{ZnO}$ nanoparticles doped 5CB samples. XRD data also reveals the same feature. XRD pattern of 5CB, $\mathrm{ZnO}$ nanoparticles and n5CB are shown in Fig.-7. Table-2 shows the XRD studies of pure 5CB and nano doped 5CB (n5CB). From the table, it is observed that Bragg angle of $n 5 \mathrm{CB}$ is more compared to pure $5 \mathrm{CB}$ and this indicates that plane orientations of $5 \mathrm{CB}$ lattice have changed remarkably due to the presence of $\mathrm{ZnO}$ nanoparticles. Due to this interplanar spacing also decreased in the doped sample and particle size is increased in n5CB.Following are the parameters calculated from XRD data and are tabulated in Table-2. 
Table-2: Particle size and Bragg's angle of prepared samples from XRD

\begin{tabular}{c|c|c|c|c}
\hline Sample & $\begin{array}{c}\Theta_{\mathrm{B}} \\
\text { (in degrees) }\end{array}$ & $\begin{array}{c}\text { FWHM } \\
\text { (in degrees) }\end{array}$ & $\begin{array}{c}<\mathrm{l}> \\
\text { (in } \mathrm{A}^{0} \text { ) }\end{array}$ & $\begin{array}{c}\mathrm{d} \\
\text { (in } \mathrm{A}^{0} \text { ) }\end{array}$ \\
\hline $5 \mathrm{CB}$ & 2.9395 & 2.961 & 27.87 & 15.03 \\
\hline $\mathrm{n} 5 \mathrm{CB}$ & 3.96534 & 1.7892 & 46.42 & 11.13 \\
\hline
\end{tabular}

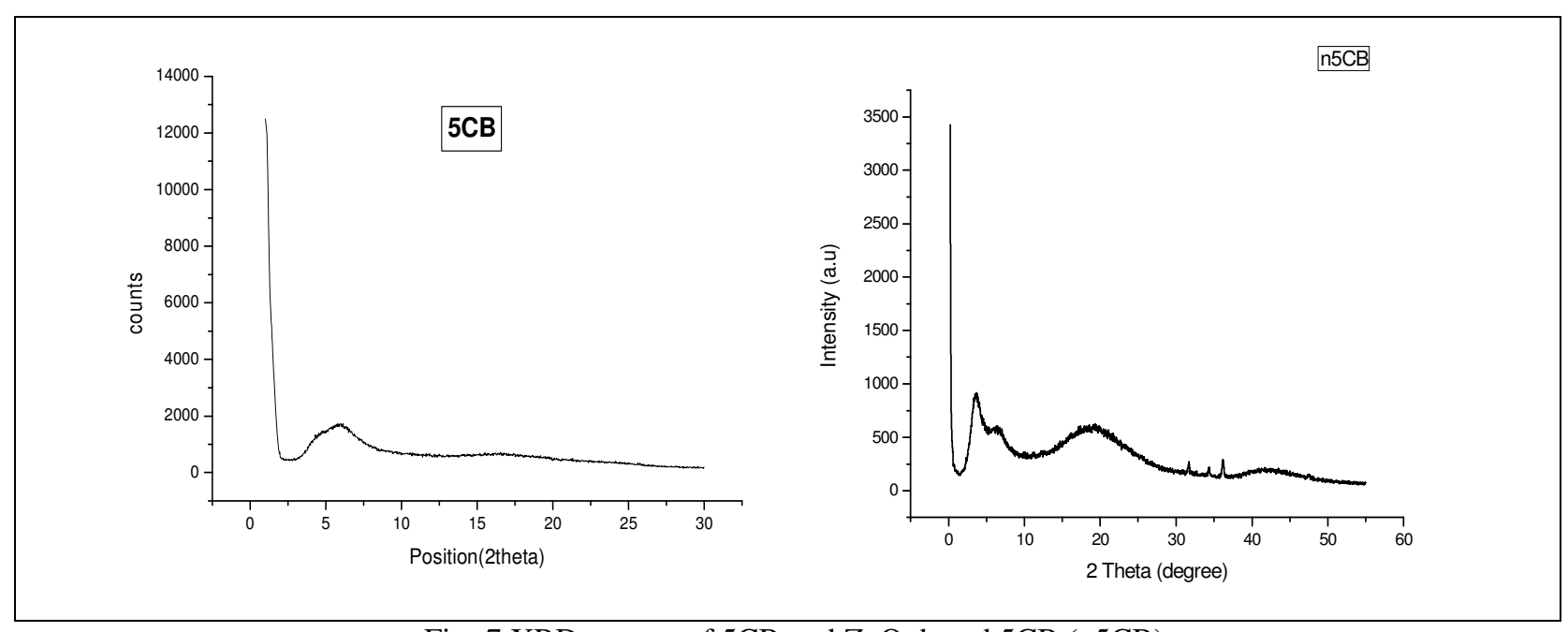

Fig.-7 XRD pattern of 5CB and $\mathrm{ZnO}$ doped 5CB (n5CB)

\section{CONCLUSIONS}

From POM, Image analysis and $\mathrm{XRD}$ studies of $\mathrm{n} 5 \mathrm{CB}$, we can conclude that $\mathrm{ZnO}$ nanoparticles systematically set the molecular alignment of 5CB lattice and this helps to decrease the entropy of the system. Birefringence nature of liquid crystalline $n 5 \mathrm{CB}$ was enhanced, which can be assigned due to the decrease in optical absorbance of the sample. Particle size was also decreased compared to the pure counterpart, which can be considered due to the nanosize effect of $\mathrm{ZnO}$. All these conclusions have again made us predict the prepared n5CB for energy applications in display devices with low threshold voltage and possibly low switching time. Hence, $\mathrm{ZnO}$ nanoparticles doped 5CB can be suggested as carbon-based materials for energy applications.

\section{REFERENCES}

1. Frederic J. Kahn, App. Phys. Lett., 20, 199(1972).

2. G. Singh, G. Vijaya Prakash, S. Kaur, A. Choudhary and A. M. Biradar, Physica B.,403, 18 (2008).

3. C. Kavitha, N. Pongali Satya Prabhu and M. L.N.Madhu Mohan, Phase Transit., 85, 11(2012).

4. P.K.Mandal, A.Lapanik, R.Wipf, B.Stuehn and W.Haase, App. Phys.Lett., 100, 073112(2012).

5. I. C. Khoo, A. Diaz, S. Kubo, J. Liou, M. Stinger, T. Mallouk and J. H. Park, Mol. Cryst. Liq. Cryst., 485, 1(2008).

6. Y. Shiraishi and N. Toshima, App. Phys.Lett., 81, 157(2002).

7. P. K. Tripathi, A. K. Misra, S. Manohar, S. K. Gupta and R. Manohar, J. Mol. Struct.,1035, 371(2013).

8. Y. Reznikov, O. Buchnev, O.Tereshchenko, V.Reshetnyak, A.Glushchenko and J.West, App. Phys. Lett., 82, 12(2003).

9. S. Tripathi, P. Ganguly, D. Haranath, W. Haase and A. M. Biradar, App. Phys. Lett.,102,063115, (2013).

10. C. I. Cheon, L. Li, A. Glushchenko, J. L. West, Y. Reznikov, J. S. Kim and D. H. Kim, SID. Symp. Dig. Tech. Papers., 36, 1(2005).

11. Hao-Hsun Liang and J-Y Lee, Liq. Cryst., 37, 3 (2010).

12. N. Goswami and Dhirendra Kumar Sharma, Physica E., 42, 1417 (2010). 
RASĀYAN $J$. Chem.

Vol. 10 | No. 1 |37-45 | January - March | 2017

13. Napaporn Thaweesaeng, Sineenart Supankit, Wicharn Techidheer and WisanuPecharapa, Energy Procedia., 34, 682 (2013).

14. R. Chauhan, A. Kumar and R. P. Chaudhary, J. Chem. Pharm. Res.,2(4), 178 (2010).

15. K. Nejati, Z. Rezvani and R. Pakizevand, Int. Nano Lett., 1(2), 75 (2011).

16. Sonal Singhal, Japinder Kaur, TseringNamgyal and Rimi Sharma, Physica B., 407, 1223 (2012).

17. K. Milenova, I. Stambolova, V. Blaskov, A. Eliyas, S. Vassilev and M. Shipochka, J. Chem. Technol. Metall.,48,259 (2013).

18. Surabhi Siva Kumar, Putcha Venkateswarlu, VankaRanga Rao and G.Nageswara Rao, Int. Nano Lett.,3, 30 (2013).

19. M. Popa, A. Mesaros, R.A. Mereu, R. Suciu, B.S. Vasile, M.S. Gabor, L. Ciontea and T. Petrisor,J.Alloy Compd.,574,255 (2013).

20. G.W.Gray, Molecular Structure and the properties of Liquid Crystals, Academic press, New York, (1962).

21. S. S. Sastry, K. Mallika, B. G. Sankara Rao, S. T. Ha, and S. Lakshminarayana, Liq. Cryst., 39, 6(2012).

22. S. S. Sastry, S. S. Begum, K. Mallika, K. B. Mahalakshmi and Ha Sie Tiong, Int. J. Inn. Res. Sci. Engg. Tech., 2, 9(2013).

23. S. Salma Begum, T. Vindhya Kumari, C. Ravi Shankar Kumar and S. Sreehari Sastry, J. NonCryst.Solids, 357, 1745 (2011).

24. Mashooq Khan, Soo-Young Park, Biosensors Bioelectronics, 68, 404 (2015).

25. N. Lebovka, V. Melnyk, Ye. Mamunya, G. Klishevich, A. Goncharuk and N. Pivovarova, Physica E., 52, 65 (2013).

26. S. Salma Begum and K. V. S. N. Raju, In Proceedings of International Conference on Maths, Physics, and Allied Sciences, Nuvem, Goa, P112A (2016).

27. S. Sreehari Sastry, S.T.Ha, B.Gowri Sankara Rao, K. Mallika and T.Vindhya Kumari, Liq. Cryst.,39, 11(2012).

28. S.SreehariSastry, B.Gowri Sankara Rao, K.B.Mahalakshmi, K. Mallika, C. Nageswara Rao and Ha Sie Tiong, ISRN Cond. Mat. Phys.2012, 423650(2012).

29. V. M. Lenart, R. F. Turchiello and S. L .Gomez, Liq. Cryst., 43, 9 (2016).

[RJC-1534/2016] 